\title{
PROPOSAL OF FAULT CHARACTERIZATION IN AUTOMOTIVE FLEXIBLE MANUFACTURING SYSTEMS (FMS)
}

\author{
André José de Queiroz Padilha1, Gabriela Ventura Silva², Guilherme Canuto da \\ Silva ${ }^{1}$, Paulo Carlos Kaminski ${ }^{3}$ \\ ${ }^{1}$ Federal University of $A B C$ \\ ${ }^{2}$ Technical University Braunschweig \\ ${ }^{3}$ Polytechnic School of the University of São Paulo \\ E-mails: andre.padilha@aluno.ufabc.edu.br, g.ventura-silva@tu-bs.de, \\ guilherme.canuto@ufabc.edu.br, pckamins@usp.br
}

\begin{abstract}
Flexible manufacturing systems (FMS) have a high degree of automation, complexity and flexibility, making it possible to manufacture multiple models of products within the same manufacturing cell with few layout changes. In this environment, intermittent and/or random faults are caused by various agents. Consequences of such faults could vary from short production downtime to irreversible loss of planned volumes. Although there are several methods to identify modes of failures and the corresponding criticality, no methods were found to characterize faults with respect to its nature. The importance of such characterization range from manufacturing design to root cause identification. This paper proposes a procedure to characterize faults in FMS. The work is divided in an introduction, four sections and a conclusion. In section one the methodology is presented. In section two the theoretical background is developed. Section three presents results of a survey applied to collect data about the importance and understanding of the topic. In section four the procedure is described. Finally, the conclusions are presented as well as recommendations for future studies.
\end{abstract}

\section{INTRODUCTION}

Customer requirements and industry competitiveness are constantly increasing, leading manufacturing systems to respond accordingly. In this context, Flexible Manufacturing System (FMS) were created. They consist of numerically controlled machining centers linked together by an automated material handling system, and can be quickly configured to produce multiple types of products [1]. This gives FMSs the capability of adapting to shifting product demands, shorter product life cycles, higher product variety, higher quality and shorter delivery times [2].

Since FMSs have a high degree of automation, the time frame which processes occurs is much shorter when compared to conventional manufacturing systems. Hence any small delay could cause severe disruptions in production schedules [3]. This dependance of trouble-free operation [4] leads to several studies in the domain of fault 
analysis and diagnosis related to FMS.

There is no consensus between the difference of the terms error, failure and fault. Different technical norms and authors use these terms with different but similar meanings $[5,6,7,2]$. Rausand [8] says that it's difficult to distinguish clearly between failures and faults and that it may lead to confusion. Based on that this work will use an approach similar to Miyagi; Riascos [6], that is, the use of error, fault and failures as synonymous, although not limited only to equipments. A reasonable definition will then be that a fault causes a non-desired deviation of a system or one of its components from its normal or intended behaviour.

Any study that tries to understand manufacturing system faults or to find solutions to them should worry with fault characterization with respect to its nature. Different faults happens at different locations of a manufacturing system [9] and at different moments, hence they could require different diagnosis and resolution techniques. In order to make this as efficiently as possible, similar faults could be grouped together. Therefore all combined data generated on a specific fault group can be used to analyse it using for example statistics or machine learning.

Instead, what is commonly seen are specific solutions to specific faults, supported by traditional tools such as Failure Mode Effect Analysis (FMEA). The correct identification of failure modes is undoubtedly important to the daily operations of an existing manufacturing process. The high number of all possible malfunctions of a production system [10] on the other hand makes these traditional tools harder to use when designing a new manufacturing plant for example. This is because one would have to predict all possible failure modes that a non-existing production system could have.

There is no characterization with regard to fault nature in FMS. Isermann [11], for example, presents characteristics of different system components faults but it doesn't includes faults related to human factors or environment for example.

The objective of this study is to propose a procedure to characterize FMS faults in groups, based on previous knowledge and real cases found in the literature, as well as validate the importance of such procedure with industry and academia experts.

\section{METHODOLOGY}

The methods used in this work consisted of developing a theoretical framework and conducting a survey using a questionnaire. In order to develop the former, the authors divided the faults in FMS in seven fault groups based on previous knowledge. The groups were used as keywords in the search. The search steps and information consolidation are shown in table 1. The following information was intended to be identified from the theoretical framework: fault characterization methods, fault classifications and fault examples. The questionnaire was elaborated to be applied both in person and indirectly via a digital medium. Details of the survey are present in section 3 .

1 For the correct understanding of well-established techniques and theories, books were selected when necessary. 
Table 1 - Theoretical framework research procedure. Adapted from [12].

\begin{tabular}{|c|c|c|}
\hline & Search steps & Used information \\
\hline 1 & Define databases. & Science Direct. SpringerLink. Capes CAFe. \\
\hline 2 & Define keywords. & $\begin{array}{l}\text { Combinations of: fault, failure, error, flexible manufacturing sys- } \\
\text { tems, machine, control system, infrastructure, environment, raw } \\
\text { material, human failure, automotive }\end{array}$ \\
\hline 3 & Define search filters. & $\begin{array}{l}\text { Content: articles. }{ }^{1} \\
\text { Knowledege area: engineering. } \\
\text { Publication year: } 2000-2018\end{array}$ \\
\hline 4 & Perform search. & \\
\hline 5 & Evaluate results. & Criteria: adherence to the research subject. \\
\hline 6 & Store results. & Software: Mendeley \\
\hline
\end{tabular}

\section{THEORETICAL FRAMEWORK}

Articles and books utilized in this work are organized on table 2, containing author, year of publication for articles or first year of publication for books (sorted in descending chronological order), and a summary.

The objective of the theoretical framework was to understand fault/failure tools related to analysis and diagnosis, identify existing fault characterization procedures and select fault examples.

Although the next three techniques are not dedicated to characterize faults in the same extent as the authors pretend, it's necessary to quickly mention them to point out differences between the proposed procedure.

\subsection{Failure Mode Effects Analysis}

A failure mode is a description of a fault [8]. It's always associated with the inability of a component to perform a certain function. In a complex system, several failure modes can appear.

The Failure Mode Effects Analysis (FMEA) technique is used to correctly identify failure modes and its corresponding effects on the system. Such technique has some variations, for example Failure Modes, Effects, and Criticality Analysis (FMECA). It's most commonly used in incremental steps, i.e., used to constantly reduce fault chances.

Two of the objectives of these techniques are identifying failure mode causes and risk-reducing actions [8]. The correct utilization of FMEA will identify specific failure modes of a single and specific process or product, and the most adequate action to solve it, though this technique will not enumerate common failure characteristics among similar processes or products. 


\subsection{Ishikawa Diagram}

The Ishikawa Diagram is used to map causes of a problem. It starts with the statement of one specific problem and works by identifying causes in, usually, six groups: methods, machines, man-power (people), materials, measurement and mother-nature (environment). It's most commonly used to identify critical faults, with severe consequences.

Similarly to FMEA it only studies one problem at a time. While this makes it excellent to solve that specific problem, it makes it hard to generalize it to other problems, especially the ones that never have happened before.

\subsection{Fault tree analysis}

Fault tree analysis is a system analysis technique used to determine the root causes and probability of occurrence of a specified undesired event [13]. It does that using fault trees, a graphical representation of relations between faults in a system.

It's used to find all root causes of one specific event, but similarly to FMEA and the Ishikawa Diagram it doesn't characterize the specific problem regarding its nature and it doesn't group it with similar problems that have similar characteristics. 


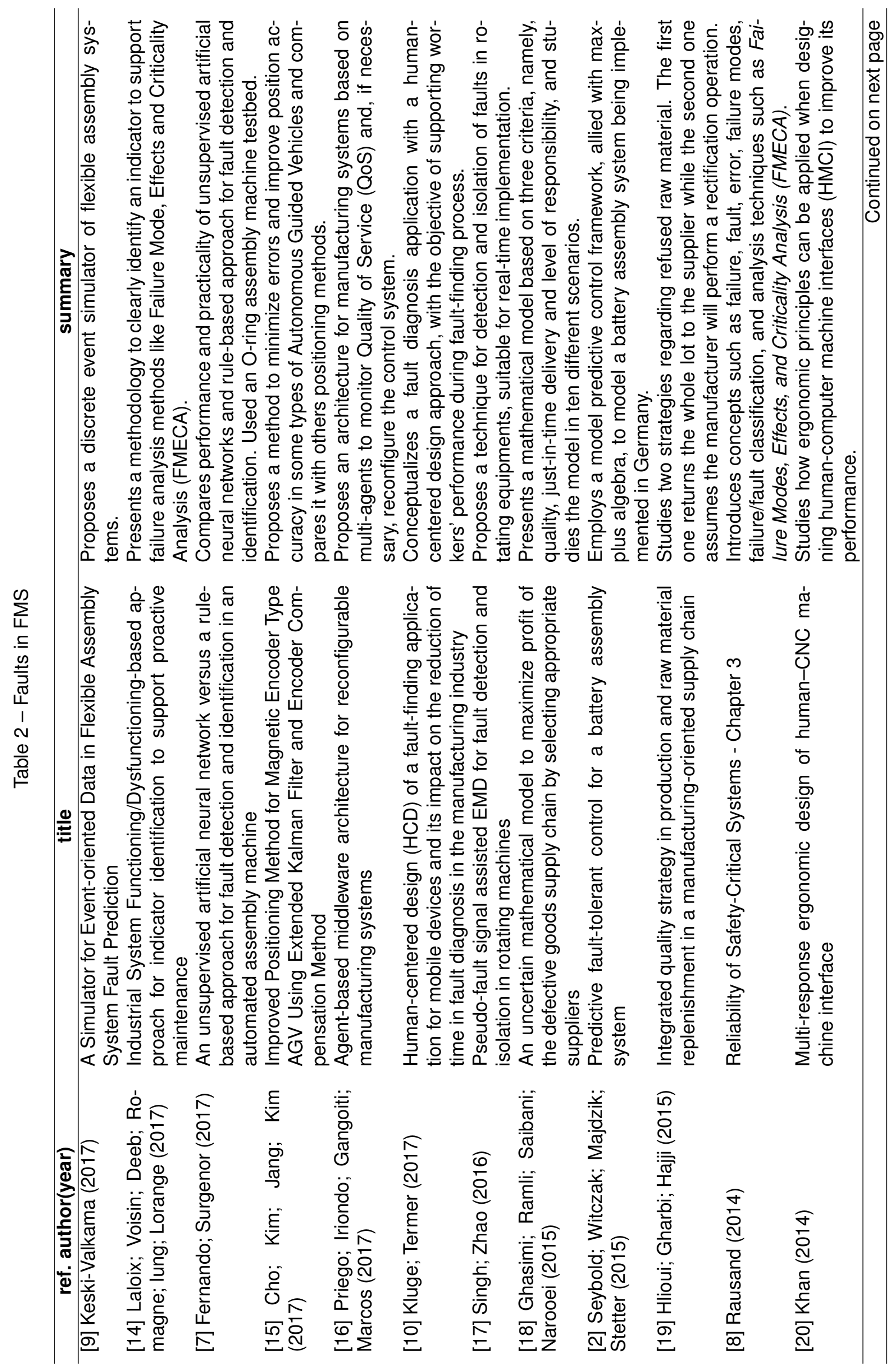




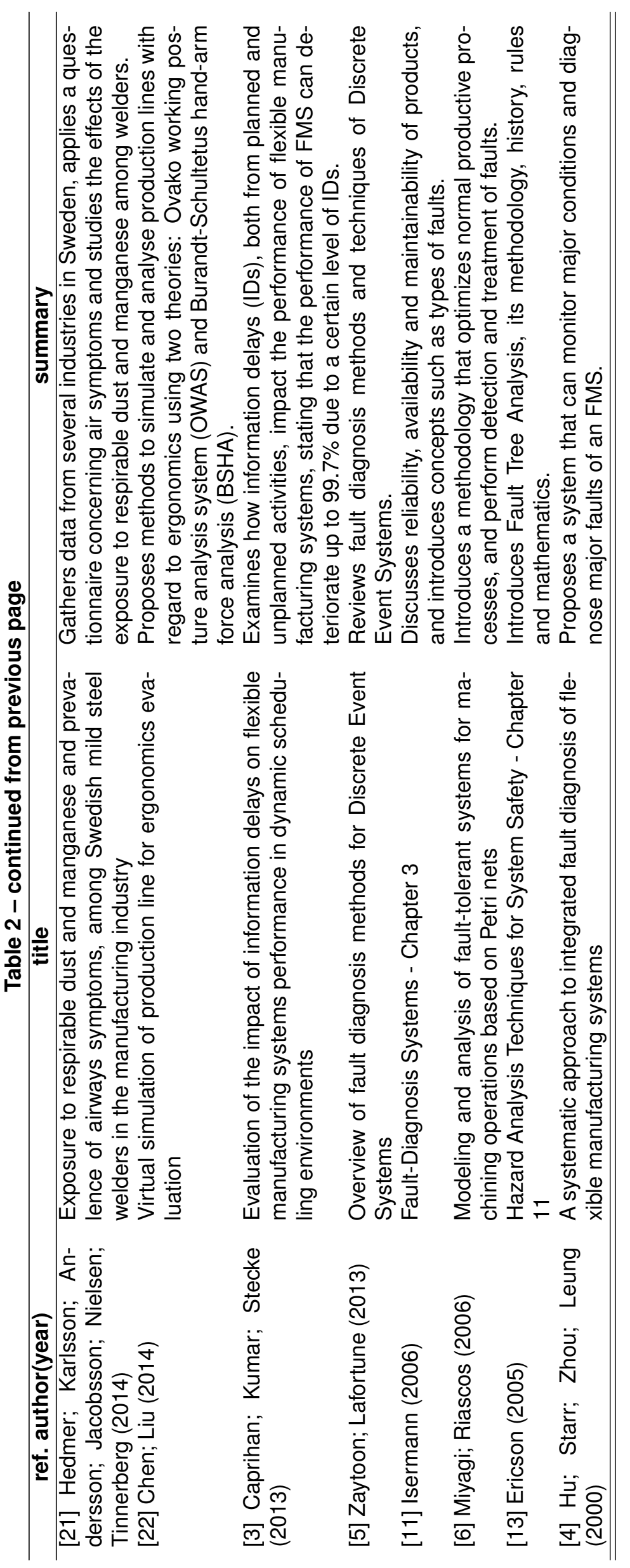




\section{FIELD RESEARCH}

Several fault examples were collected from the works present in the theoretical framework. Since no characterization with respect to faults' nature was found, they were assigned to seven groups based on authors' experience: (1) control systems, (2) machines, (3) infrastructure, (4) environment, (5) human factor, (6) raw material, (7) others. Table 3 shows the result. A survey was elaborated to test if industry and/or academia experience alone were sufficient to characterize faults according to the groups.

Table 3 - Fault groups

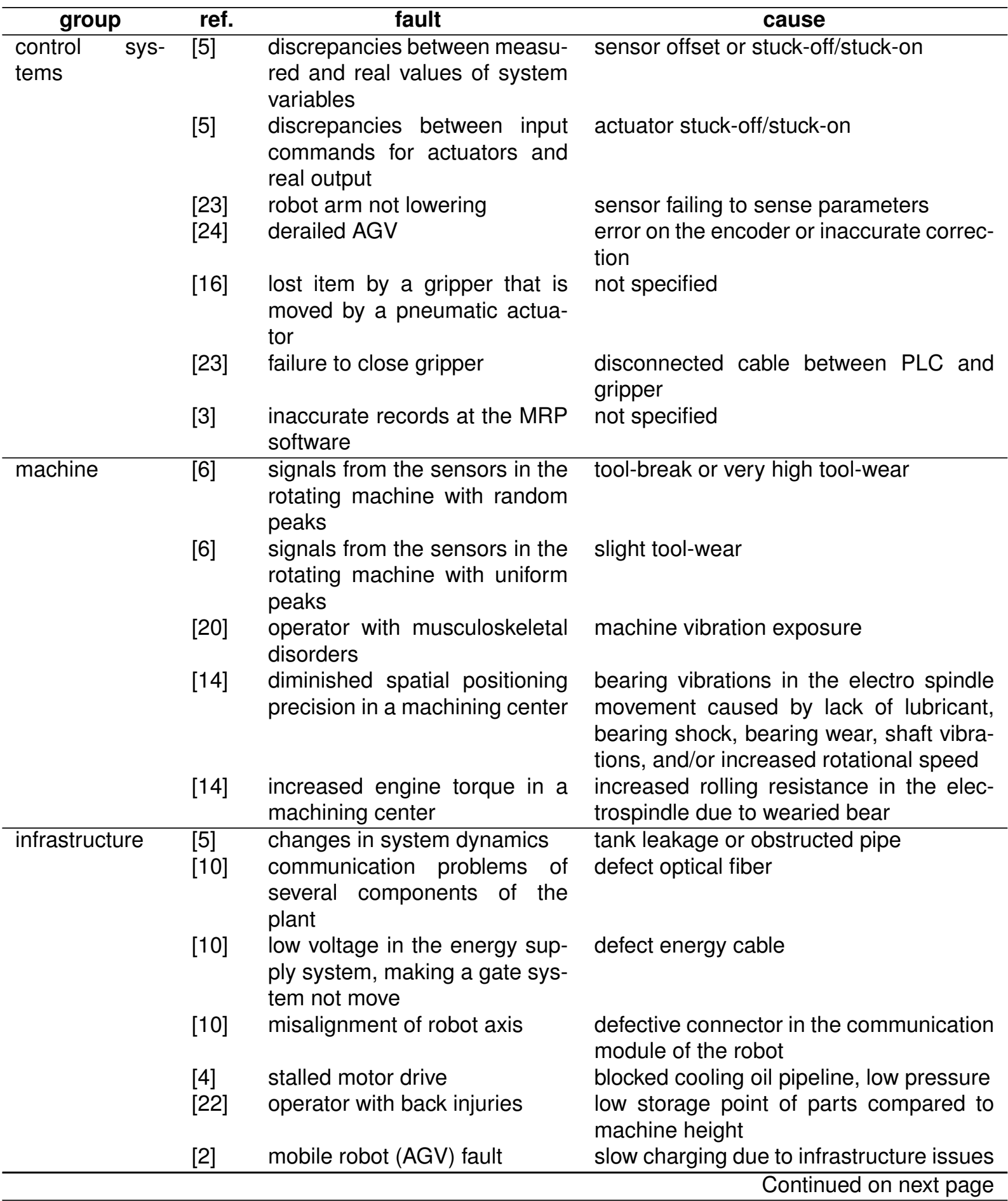


Table 3 - continued from previous page

\begin{tabular}{|c|c|c|c|}
\hline group & ref. & fault & cause \\
\hline environment & [21] & $\begin{array}{l}\text { high concentration of manga- } \\
\text { nese in the air }\end{array}$ & $\begin{array}{l}\text { poor general ventilation and training of } \\
\text { operators regarding equipment usage }\end{array}$ \\
\hline \multirow[t]{6}{*}{ human factor } & $|6|$ & $\begin{array}{l}\text { signals from the sensors in the } \\
\text { rotating machine with uniform } \\
\text { peaks }\end{array}$ & CNC programming mistake \\
\hline & 3 & $\begin{array}{l}\text { machine place and pulls parts } \\
\text { for the incorrect assembly line }\end{array}$ & incorrect program entered by an operator \\
\hline & |3 & solder paste not being placed & bottom stencil mounted when running top \\
\hline & & where it should on PCBs & $\begin{array}{l}\text { side of PCBs. Stencils are manually } \\
\text { mounted. }\end{array}$ \\
\hline & 3 & $\begin{array}{l}\text { poor solder quality on several } \\
\text { printed circuit boards (PCBs) }\end{array}$ & $\begin{array}{l}\text { operator not performing initial inspection } \\
\text { of the first PCBs produced }\end{array}$ \\
\hline & 3| & assembly line stop & $\begin{array}{l}\text { raw material with specs. altered by the } \\
\text { vendor without communicating }\end{array}$ \\
\hline \multirow[t]{2}{*}{ raw material } & {$[\overline{19]}$} & $\begin{array}{l}\text { returned raw material to sup- } \\
\text { plier }\end{array}$ & raw material out of specifications \\
\hline & [18] & defective goods produced & lack of quality in raw material \\
\hline
\end{tabular}

The survey used a questionnaire to collect respondent's professional background and his/her contact with fault characterization procedures. The questionnaire was divided in four sections. In the first section two positioning questions were presented. In section two, seven fault groups were presented and a specific question was made to characterize them. Section 3 aimed to evaluate if the respondent had any difficulty in characterizing the faults presented in section 2. Furthermore, respondent's opinion with respect to the importance of having a procedure to characterize faults in FMS was asked. Section 4 ended the questionnaire. In that section the respondent could freely describe perceptions and experiences on the topic addressed in the research.

\subsection{Pretest}

A first version of the questionnaire was applied to four people with different professional backgrounds. The objective of the pretest was to evaluate if the respondents understood what was asked in each question, as well as gather feedback to improve the questionnaire.

After reading the pretest answers some changes were made to improve it, the major ones being: Chart 1 on question 3 completely restructured, improving its readability; Likert scale questions, 5 and 6 , altered; description of problem I on question 3 complemented with more information; addition of two other problems inside the raw material group. A final version of the questionnaire is on appendix $A$.

\subsection{Data collection}

The questionnaire was applied to a total of 29 people mainly from the automotive industry. This was done through an on-line version of the questionnaire submitted to professional contacts of the authors and a physical version of the 
questionnaire applied to a class of the automotive engineering specialization course at the Automotive Engineering Center in POLI-USP.

There was only one criterion to exclude a respondent's questionnaire: not answering a third or more of the total number of questions or items. With this criterion all of the 29 respondents' answers were considered in the analysis.

Respondents' profile is presented on tables 4, 5and 6.

Table 4 - Respondents' institution sector

\begin{tabular}{cc}
\hline Sector & $\begin{array}{c}\text { Number of } \\
\text { respondents }\end{array}$ \\
\hline Automaker & 6 \\
OEM & 7 \\
Engineering & 2 \\
projects & 1 \\
Academia & 10 \\
Other & 3 \\
Blank & \\
\hline
\end{tabular}

Table 5 - Respondents' institution position

\begin{tabular}{cc}
\hline Position & $\begin{array}{c}\text { Number of } \\
\text { respondents }\end{array}$ \\
\hline Management & 7 \\
Technical & 17 \\
Administration & 2 \\
Operations & 0 \\
Blank & 3 \\
\hline
\end{tabular}

Table 6 - Respondents' period of employment

\begin{tabular}{cc}
\hline Period of Employment & $\begin{array}{c}\text { Number of } \\
\text { respondents }\end{array}$ \\
\hline$<1$ year & 4 \\
$\geq 1$ year and $<2$ years & 1 \\
$\geq 2$ years and $<5$ years & 8 \\
$\geq 5$ years and $<10$ years & 5 \\
$\geq 10$ years & 8 \\
Blank & 3 \\
\hline
\end{tabular}

\subsection{Results}

Questions 1 to 6 in the questionnaire will be referred respectively as Q1 to Q6. Answers to Q1 and Q2 are presented on tables 7 and 8 respectively. Q2 answers were considered only when the respondent answered "Yes" on Q1.

Table 7 - Question 1 - absolute and relative fre- Table 8 -Question 2 - absolute and relative frequency of answers quency of answers

\begin{tabular}{ccc}
\hline Answer & $\begin{array}{c}\text { Absolute } \\
\text { frequency }\end{array}$ & $\begin{array}{c}\text { Relative } \\
\text { frequency }\end{array}$ \\
\hline Yes & 15 & $51.72 \%$ \\
No & 10 & $34.48 \%$ \\
I don't know & 3 & $10.34 \%$ \\
Blank & 1 & $3.45 \%$ \\
\hline
\end{tabular}

\begin{tabular}{ccc}
\hline Answer & $\begin{array}{c}\text { Absolute } \\
\text { frequency }\end{array}$ & $\begin{array}{c}\text { Relative } \\
\text { frequency }\end{array}$ \\
\hline Yes & 10 & $66.67 \%$ \\
No & 5 & $33.33 \%$ \\
Blank & 0 & $0 \%$ \\
\hline
\end{tabular}

Answers to each item of Q3 are presented with column charts on appendix B, indicating the number of answers per fault group. A consolidated view of the data is on figure 1 . 


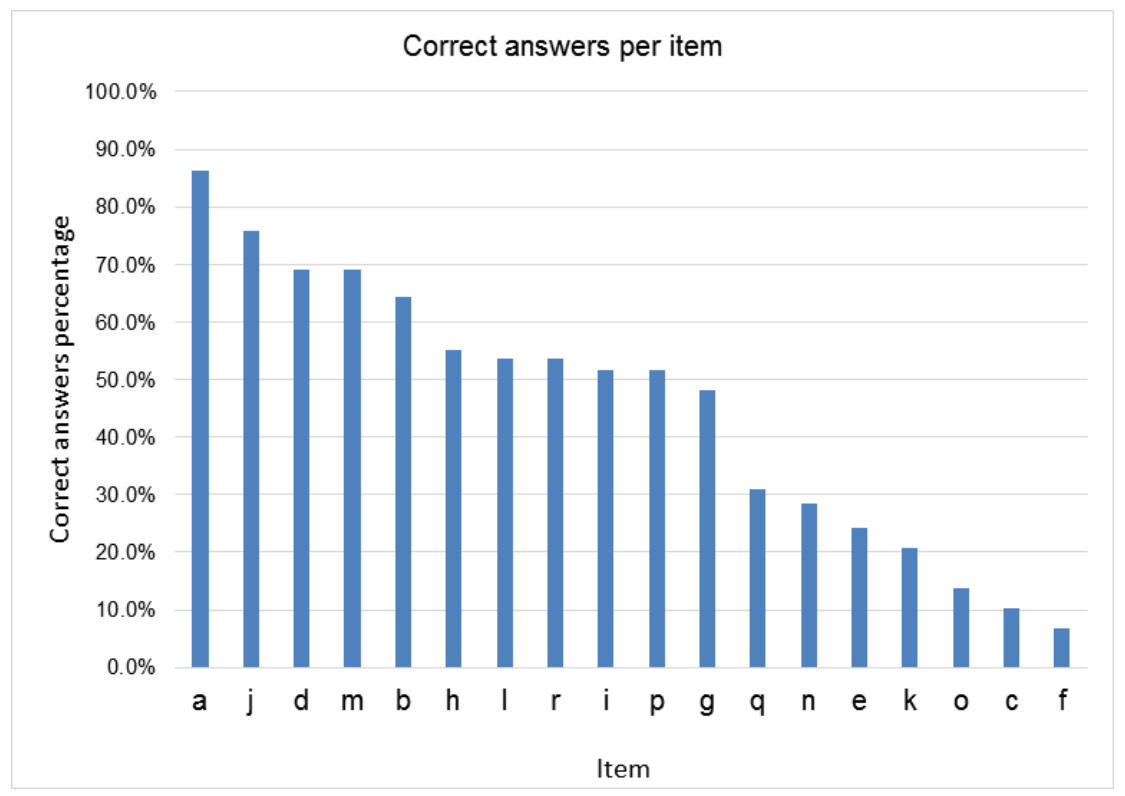

Figure 1 - Percentage of correct answers per item on Q3.

Only one item, a, attained more than $80 \%$ of correct answers. Thirteen items attained less than $60 \%$ of correct answers.

Finally, answers to Q4 and Q5 are presented on figures 2 and 3 respectively.

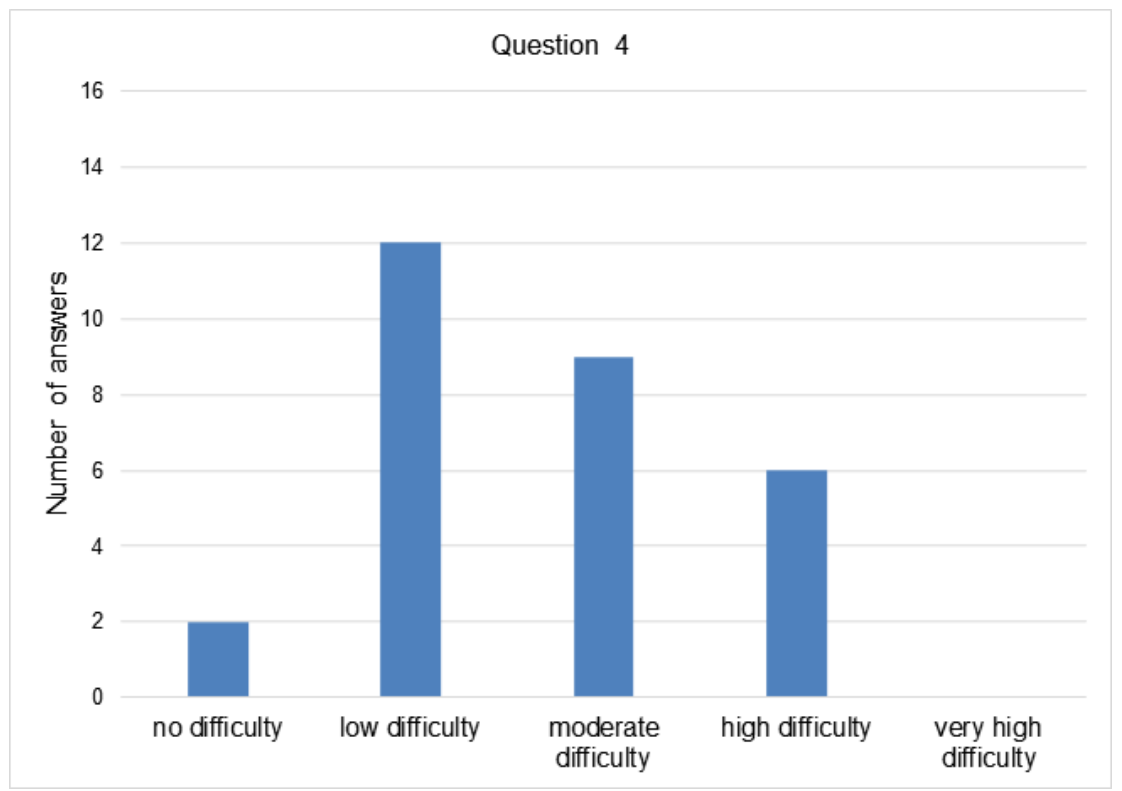

Figure 2 - Answers of all respondents to Q4.

Analysing answers to Q5 shows that 22 respondents consider that a clear procedure, for example a flowchart, would be of high or very high importance to help them answer Q3. 


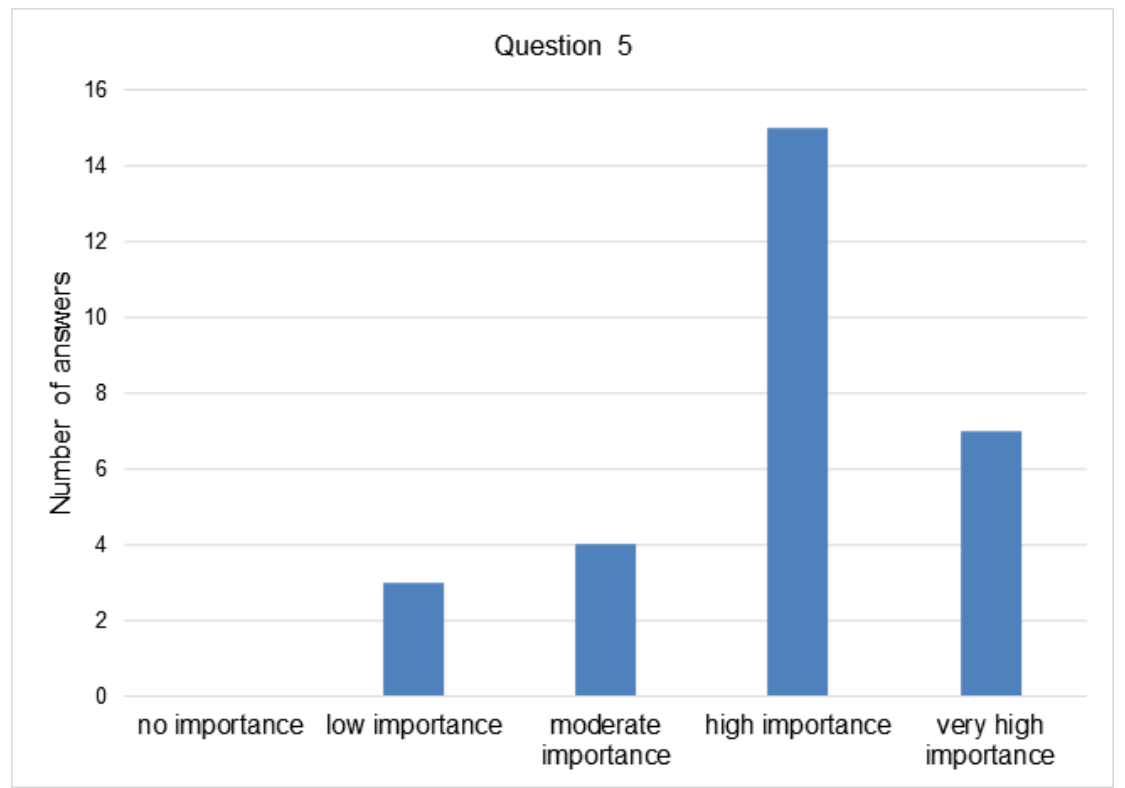

Figure 3 - Answers of all respondents to Question 5.

\section{PROPOSED PROCEDURE}

In order to be able to group similar faults together in a structured manner a procedure is proposed. Each fault group proposed in section 3 is now characterized in section 4.1. The procedure is then introduced in section 4.2 .

\subsection{FAULT CHARACTERIZATION}

Control systems: any fault identified in components of a control system, whether open-loop, closed-loop or ubiquitous computing. It includes sensors, actuators, Programmable Logic Controller (PLC), open distributed computing system, and embedded software.

Machines: any fault identified in equipments used in the transformation of raw material into components or finished goods. It includes processing support devices such as fixturing systems, inter-process devices, and others that add more value directly to the products.

Infrastructure: in this group faults should be characterized in five subgroups: (1) civil: any fault regarding industrial plant constructions, such as earthwork, foundation, buildings, bridges, structures, and equipments or machines layout. (2) electric: any fault regarding supply and use of electric power. It includes electrical substations, transformers, electrical panels, and wiring. (3) mechanical: any fault regarding mechanical systems of the industrial plant. It includes compressed air generation and distribution systems, transfer systems, air conveyor, and other transportation or lifting systems. (4) hydraulic and sanitary: any fault regarding collection, storage, and distribution of industrial fluids. It includes reservoirs, piping, and all singularities required for operation and safety. It also includes systems for collecting, treating and disposing sanitary facilities 
fluids, as well as clean water supply network. (5) information: any fault regarding data collection, mining, treatment, storage, and distribution required for industrial plant operation. It includes physical or cloud servers, network architectures, cabling, routers, switches and all devices required for data traffic. It also includes infrastructure for private network extension across the internet (virtual private networks).

Environment: any fault regarding the transformation environment, with or without the presence of humans. It includes noise, ambient air, temperature, odor and visual pollution, human exposure and unhealthy conditions.

Human factors: any fault of human origin that is linked to the non-execution of a guideline, method, procedure, work instruction, or protocol of performance. It includes execution of direct transformation, maintenance, safety and conduct activities.

Raw material: any fault identified directly or indirectly in the raw material. It includes processing, structure (microscopy), and properties. The performance of the component or final product must be observed.

Others: any fault that can not be characterized in the 6 previous groups. Faults of this group should be assigned using an exclusion criterion, given that the groups were already characterized.

\subsection{CHARACTERIZATION PROCEDURE}

The procedure consists of a flowchart (figure 4) and a summary table of each group characteristics (table 9).

Table 9 - Group characteristics summary

\begin{tabular}{ll}
\hline \multicolumn{1}{c}{ group } & \multicolumn{1}{c}{ characteristics } \\
\hline control systems & $\begin{array}{l}\text { sensors, actuators, PLC, open distributed computing systems, embed- } \\
\text { ded software. }\end{array}$ \\
machine & transformation equipment, fixturing systems, inter-process devices. \\
infrastructure & buildings and structures, equipment layout; electrical substations, trans- \\
& formers, panels, wirings; compressed air devices, transfer systems, air \\
& conveyor, transportation and lifting systems; industrial fluid reservoirs, \\
& piping, singularities, sanitary facilities and clean water supply network; \\
& physical or cloud servers, cabling, information network devices. \\
environment & noise, ambient air, temperature, odor and visual pollution, human expo- \\
& sure and unhealthy conditions. \\
human factor & non-execution of guidelines and work instructions, execution of direct \\
raw material & transformation, maintenance, safety and conduct activities. \\
other & raw material structure (microscopy), properties and processing. \\
\hline \hline
\end{tabular}




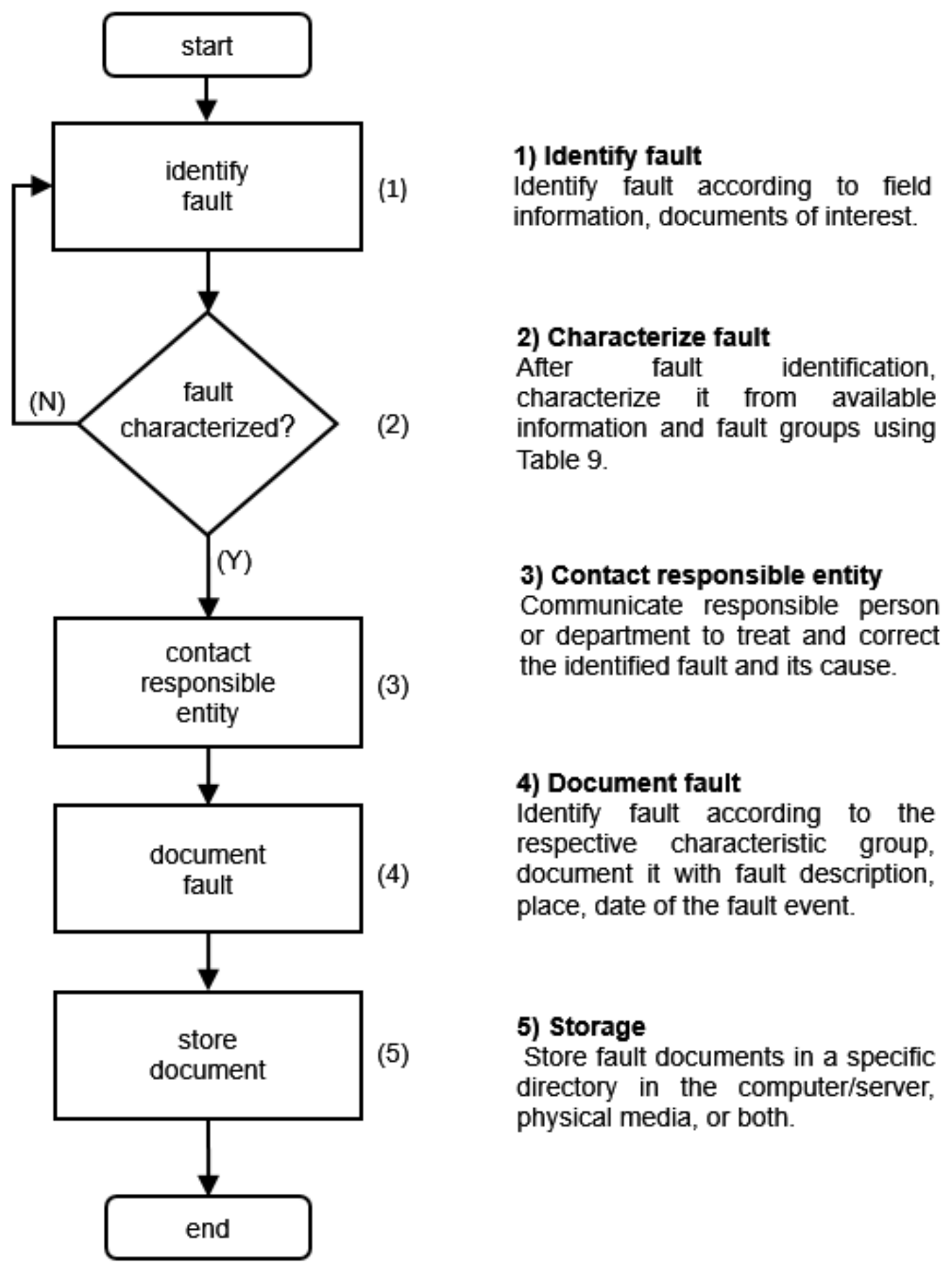

Figure 4 - Flowchart.

Although the proposed procedure could be simplified with only steps 1 and 2 of the flowchart, step 3 is essential to the daily activity of industries, while steps 4 and 5 should be used to improve the procedure itself, by analysing past fault data and improving each fault group characterization. 


\section{CONCLUSIONS}

The theoretical framework revealed the lack of procedures to characterize faults according to its nature. To fill in this gap, a procedure using seven fault groups based on authors' experience and literature fault examples was proposed.

The field research showed that only academia or industry expertise is not enough to characterize faults according to the proposed groups. Most respondents did not correlate appropriately the fault to its fault group. The majority of respondents didn't agree to which group each fault should be assigned to.

Further studies should validate the proposed procedure, repeating the survey with the same faults used in this work, among industry and academia experts using it. New fault examples can be utilized. The procedure would then be measured against the convergence of respondents' answers to a single group.

\section{REFERENCES}

[1] BAŞAK, Özkan; ALBAYRAK, Y. Esra. Petri net based decision system modeling in real-time scheduling and control of flexible automotive manufacturing systems. Computers \& Industrial Engineering, v. 86, p. 116-126, 2015.

[2] SEYBOLD, Lothar; WITCZAK, Marcin; MAJDZIK, Paweł; STETTER, Ralf. Predictive fault-tolerant control for a battery assembly system.

IFAC-PapersOnLine, v. 28, n. 21, p. 476-483, 2015.

[3] CAPRIHAN, Rahul; KUMAR, Ashok; STECKE, Kathryn E. Evaluation of the impact of information delays on flexible manufacturing systems performance in dynamic scheduling environments. The International Journal of Advanced Manufacturing Technology, v. 67, n. 1-4, p. 311-338, 2013.

[4] HU, W; STARR, A.G.; ZHOU, Z; LEUNG, A.Y.T. A systematic approach to integrated fault diagnosis of flexible manufacturing systems. International Journal of Machine Tools and Manufacture, v. 40, n. 11, p. 1587-1602, set. 2000.

[5] ZAYTOON, J; LAFORTUNE, S. Overview of fault diagnosis methods for Discrete Event Systems. Annual Reviews in Control, v. 37, n. 2, p. 308-320, 2013.

[6] MIYAGI, P. E.; RIASCOS, L. A M. Modeling and analysis of fault-tolerant systems for machining operations based on Petri nets. Control Engineering Practice, v. 14, n. 4, p. 397-408, 2006.

[7] FERNANDO, Heshan; SURGENOR, Brian. An unsupervised artificial neural network versus a rule-based approach for fault detection and identification in an automated assembly machine. Robotics and Computer-Integrated Manufacturing, v. 43, p. 79-88, 2017.

[8] RAUSAND, Marvin. Reliability of Safety-Critical Systems. Hoboken, NJ, USA: John Wiley \& Sons, Inc., jan. 2014.

[9] KESKI-VALKAMA, Tero. A Simulator for Event-oriented Data in Flexible Assembly System Fault Prediction. Procedia Computer Science, v. 119, n. 2017, p. 121-130, 2017. 
[10] KLUGE, Annette; TERMER, Anatoli. Human-centered design ( HCD ) of a faultfinding application for mobile devices and its impact on the reduction of time in fault diagnosis in the manufacturing industry. Applied Ergonomics, v. 59, p. 170-181, 2017.

[11] ISERMANN, Rolf. Fault-Diagnosis Systems. Berlin, Heidelberg: Springer Berlin Heidelberg, 2006.

[12] CANUTO DA SILVA, Guilherme. Tutorial para Realização de Pesquisa Bibliográfica e Estruturação de Trabalhos Acadêmicos (notas de aula), 2017.

[13] ERICSON, Clifton A. Hazard Analysis Techniques for System Safety. Hoboken, NJ, USA: John Wiley \& Sons, Inc., jul. 2005.

[14] LALOIX, T.; VOISIN, A.; DEEB, S.; ROMAGNE, E.; IUNG, B.; LORANGE, F. Industrial System Functioning/Dysfunctioning-Based Approach for Indicator Identification to Support Proactive Maintenance. IFAC-PapersOnLine, v. 50, n. 1, p. 13704-13709, jul. 2017.

[15] CHO, Hyunhak; KIM, Eun Kyeong; JANG, Eunseok; KIM, Sungshin. Improved positioning method for Magnetic Encoder type AGV using Extended Kalman Filter and Encoder Compensation Method. International Journal of Control, Automation and Systems, v. 15, n. 4, p. 1844-1856, 2017.

[16] PRIEGO, Rafael; IRIONDO, Nagore; GANGOITI, Unai; MARCOS, Marga. Agent-based middleware architecture for reconfigurable manufacturing systems. The International Journal of Advanced Manufacturing Technology, v. 92, n. 5-8, p. 1579-1590, 2017.

[17] SINGH, Dheeraj Sharan; ZHAO, Qing. Pseudo-fault signal assisted EMD for fault detection and isolation in rotating machines. Mechanical Systems and Signal Processing, v. 81, p. 202-218, 2016.

[18] GHASIMI, Salah Alden; RAMLI, Rizauddin; SAIBANI, Nizaroyani; NAROOEI, Khashayar Danesh. An uncertain mathematical model to maximize profit of the defective goods supply chain by selecting appropriate suppliers. Journal of Intelligent Manufacturing, p. 1-16, dez. 2015.

[19] HLIOUI, Rached; GHARBI, Ali; HAJJI, Adnène. Integrated quality strategy in production and raw material replenishment in a manufacturing-oriented supply chain. The International Journal of Advanced Manufacturing Technology, v. 81, n. 1-4, p. 335-348, out. 2015.

[20] KHAN, Imtiaz Ali. Multi-response ergonomic design of human-CNC machine interface. International Journal on Interactive Design and Manufacturing (IJIDeM), v. 8, n. 1, p. 13-31, fev. 2014.

[21] HEDMER, Maria; KARLSSON, Jan-Eric; ANDERSSON, Ulla; JACOBSSON, Helene; NIELSEN, Jörn; TINNERBERG, Håkan. Exposure to respirable dust and manganese and prevalence of airways symptoms, among Swedish mild steel welders in the manufacturing industry. International Archives of Occupational and Environmental Health, v. 87, n. 6, p. 623-634, ago. 2014.

[22] CHEN, Ming; LIU, Jin-Fei. Virtual simulation of production line for ergonomics evaluation. Advances in Manufacturing, v. 2, n. 1, p. 48-53, mar. 2014.

[23] SEKAR, Ramnath; HSIEH, Sheng Jen; WU, Zhenhua. Remote diagnosis design for a PLC-based automated system: 2-evaluation of factors affecting remote diagnosis performance. International Journal of Advanced Manufacturing Technology, p. 1-19, 2012. 
[24] CHO, Hyunhak; KIM, Eun Kyeong; JANG, Eunseok; KIM, Sungshin. Improved positioning method for Magnetic Encoder type AGV using Extended Kalman Filter and Encoder Compensation Method. International Journal of Control, Automation and Systems, v. 15, n. 4, p. 1844-1856, 2017.

\section{APPENDIX}

\section{A - Final questionnaire}

Section 1: initial questions.

\begin{tabular}{|l|l|l|l|l|}
\hline INITIAL QUESTIONS \\
\hline Question 1: & $\begin{array}{l}\text { Does the institution where you work have } \\
\text { any fault characterization procedure? }\end{array}$ & $\bigcirc$ Yes & $\bigcirc$ No & $\begin{array}{l}\bigcirc \text { I don't } \\
\text { know }\end{array}$ \\
\hline Question 2: & $\begin{array}{l}\text { If it does, do you know and/or utilize this } \\
\text { procedure? }\end{array}$ & $\bigcirc$ Yes & & $\bigcirc$ No \\
\hline
\end{tabular}

\section{Section 2: fault characterization.}

Question 3: Classify each problem presented in the following chart with the following groups: (1) control systems. (2) machine. (3) infrastructure. (4) environment. (5) human factor. (6) raw material. (7) other. Choose the group that better characterize the corresponding problem. Attention: choose only one fault group that best characterize the corresponding problem.

Chart 1. Fault groups.

\begin{tabular}{|c|c|c|c|c|c|c|c|}
\hline \multirow[b]{2}{*}{ Problem description } & \multicolumn{7}{|c|}{ fault groups } \\
\hline & 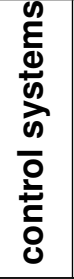 & 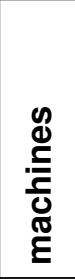 & 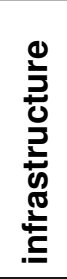 & 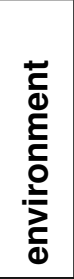 & 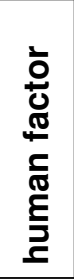 & 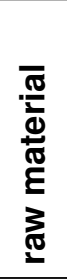 & 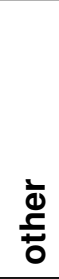 \\
\hline $\begin{array}{l}\text { a. Derailed Autonomous Guided Vehicle (AGV) caused by } \\
\text { encoder errors. }\end{array}$ & 0 & 0 & 0 & 0 & 0 & 0 & 0 \\
\hline $\begin{array}{l}\text { b. Raw material with specifications altered by the vendor } \\
\text { without communicating to purchasing or engineering team. }\end{array}$ & 0 & 0 & 0 & 0 & 0 & 0 & 0 \\
\hline $\begin{array}{l}\text { c. Defective connector in the communication module of the } \\
\text { industrial robot, causing a misalignment of its axis. }\end{array}$ & 0 & 0 & 0 & 0 & 0 & 0 & 0 \\
\hline $\begin{array}{l}\text { d. Defect optical fiber, causing a problem with the } \\
\text { communication of several components of the plant. }\end{array}$ & 0 & 0 & $\bigcirc$ & 0 & 0 & 0 & $\bigcirc$ \\
\hline $\begin{array}{l}\text { e. Arm not lowering, caused by a sensor failing to sense } \\
\text { parameters. The sensor failed because it was displaced from } \\
\text { its position due to vibrations in the assembly line. }\end{array}$ & 0 & 0 & 0 & 0 & $\bigcirc$ & 0 & 0 \\
\hline $\begin{array}{l}\text { f. Failure to close gripper, caused by a disconnected cable } \\
\text { between the PLC and the gripper. }\end{array}$ & 0 & 0 & 0 & 0 & $\bigcirc$ & 0 & D \\
\hline $\begin{array}{l}\text { g. Detected signals in a CNC with random peaks indicating } \\
\text { tool-break or very high tool-wear. }\end{array}$ & 0 & 0 & 0 & 0 & 0 & 0 & D \\
\hline $\begin{array}{l}\text { h. Detected signals in a CNC with uniform peaks indicating } \\
\text { slight tool-wear. }\end{array}$ & 0 & 0 & 0 & 0 & 0 & 0 & D \\
\hline $\begin{array}{l}\text { i. Detected signals in a CNC with uniform peaks indicating a } \\
\text { programming mistake. }\end{array}$ & 0 & 0 & 0 & 0 & 0 & 0 & D \\
\hline j. Returned raw material to the supplier due to non-conformity. & 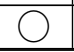 & O & O & $\bigcirc$ & $\bigcirc$ & 0 & O \\
\hline
\end{tabular}




\begin{tabular}{|c|c|c|c|c|c|c|c|}
\hline \multirow[b]{2}{*}{ Problem description } & \multicolumn{7}{|c|}{ fault groups } \\
\hline & 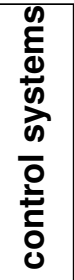 & 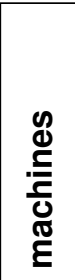 & 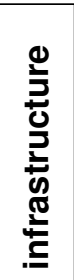 & 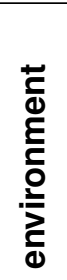 & 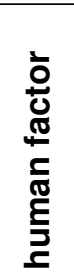 & 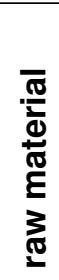 & 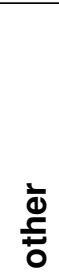 \\
\hline k. Slow Autonomous Guided Vehicle (AGV) battery charging. & 0 & 0 & 0 & 0 & 0 & $\mathrm{O}$ & $\mathrm{O}$ \\
\hline $\begin{array}{l}\text { I. Inaccurate records at the Materials Resource planning } \\
\text { software (MRP) used by the company, which in turn does not } \\
\text { reflect real inventory levels. The MRP software is updated } \\
\text { automatically throughout the factory. }\end{array}$ & $\bigcirc$ & 0 & 0 & $\bigcirc$ & $\bigcirc$ & $\bigcirc$ & O \\
\hline $\begin{array}{l}\text { m. Incorrect program entered in an industrial controller, } \\
\text { allowing machines to place and pull parts for the incorrect } \\
\text { assembly. }\end{array}$ & $\bigcirc$ & 0 & $\bigcirc$ & O & $\bigcirc$ & $\bigcirc$ & O \\
\hline $\begin{array}{l}\text { n. Injured operator due to movements done to lift parts to a } \\
\text { machine. }\end{array}$ & $\bigcirc$ & 0 & O & 0 & $\bigcirc$ & O & O \\
\hline $\begin{array}{l}\text { o. Exposure of an operator to machine vibrations causing } \\
\text { musculoskeletal disorders. }\end{array}$ & $\bigcirc$ & 0 & $\bigcirc$ & O & $\bigcirc$ & $\bigcirc$ & O \\
\hline $\begin{array}{l}\text { p. High concentration of manganese in welding processes, } \\
\text { which can cause neurotoxic effects such as changes in } \\
\text { short-term memory and reduced hand-eye coordination. }\end{array}$ & $\bigcirc$ & 0 & $\bigcirc$ & O & $\bigcirc$ & $\bigcirc$ & O \\
\hline $\begin{array}{l}\text { q. Blocked cooling oil pipeline, which in turn was caused by } \\
\text { the system not giving enough pressure. }\end{array}$ & $\bigcirc$ & 0 & $\bigcirc$ & 0 & 0 & 0 & 0 \\
\hline $\begin{array}{l}\text { r. Defective goods produced due to lack of quality of parts } \\
\text { produced by a given supplier. }\end{array}$ & 0 & 0 & 0 & 0 & 0 & 0 & 0 \\
\hline
\end{tabular}

Section 3: specific questions.

Question 4: check the difficulty degree found to fill in Chart 1 at Section 2, where the first degree indicates "no difficulty"and the fifth degree indicates "very high difficulty".

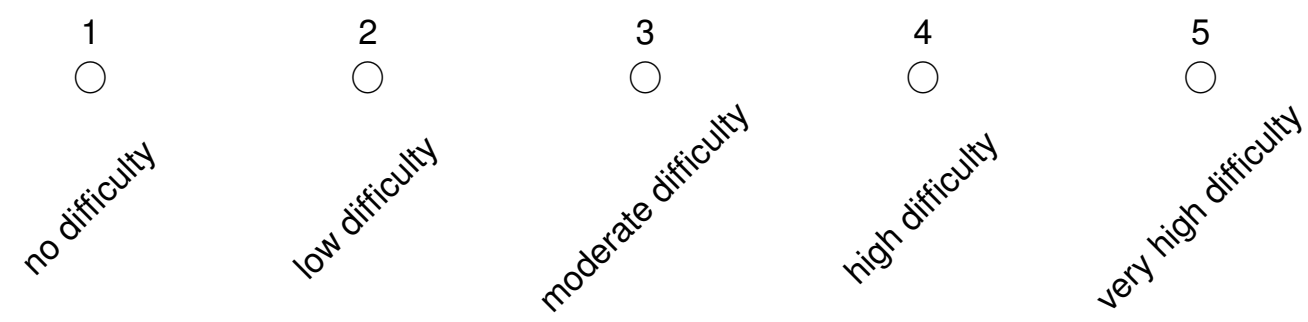

Question 5: would having a clear procedure (flowchart) to characterize faults help you filling in Chart 1 at Section 2? Check the corresponding degree of importance of having a clear procedure (flowchart) to characterize faults, where the first degree indicates "low importance"and the fifth degree indicates "very high importance". 

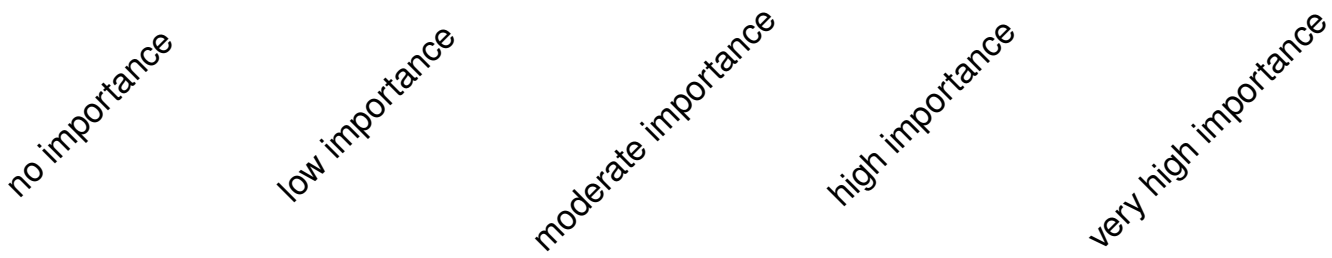

Section 4: questionnaire conclusion.

Question 6: freely describe your perceptions and experiences about the topic addressed in this research.

\section{B - Final questionnaire results}

In the following charts, red bars represents the correct group to each item (according to authors' experience).

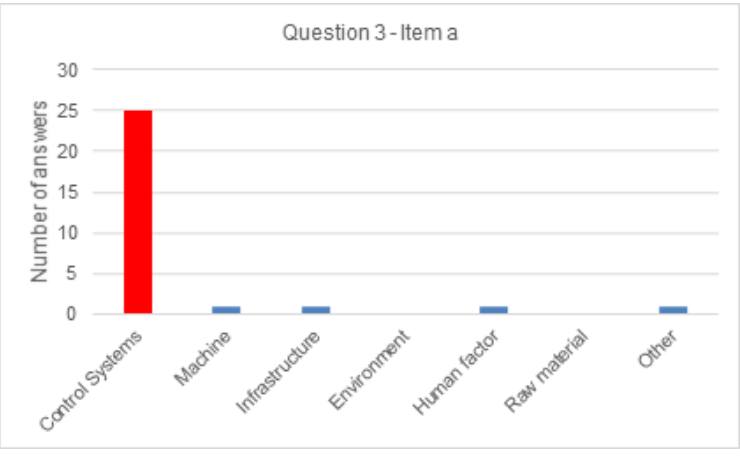

Figure B1 - Answers of all respondents to Item "a" on Question 3.

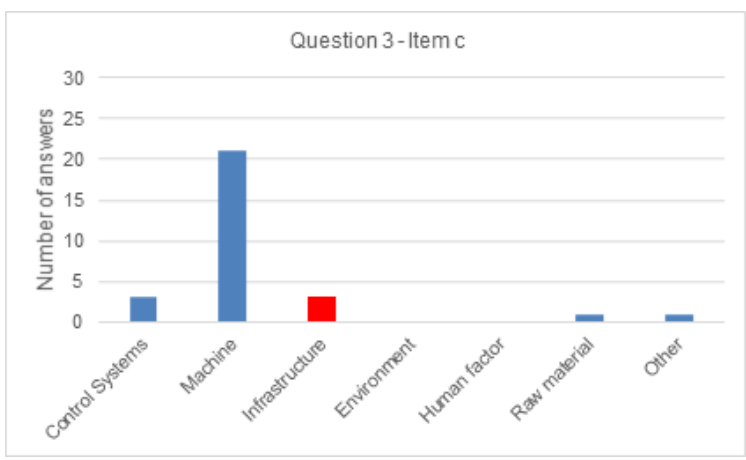

Figure B3 - Answers of all respondents to Item "c" on Question 3.

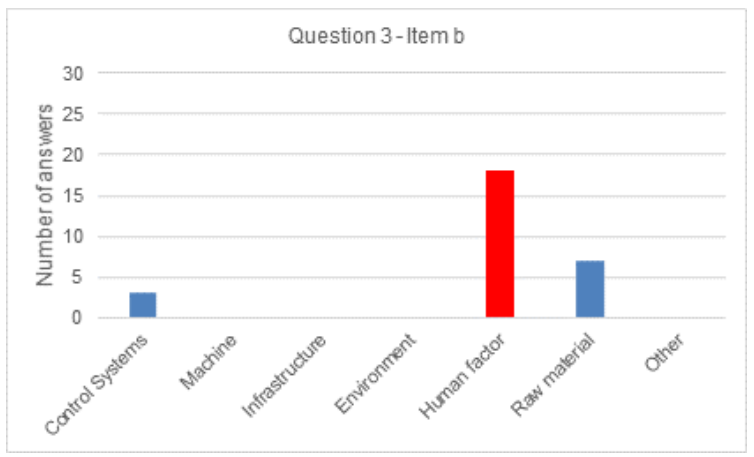

Figure B2 - Answers of all respondents to Item "b" on Question 3.

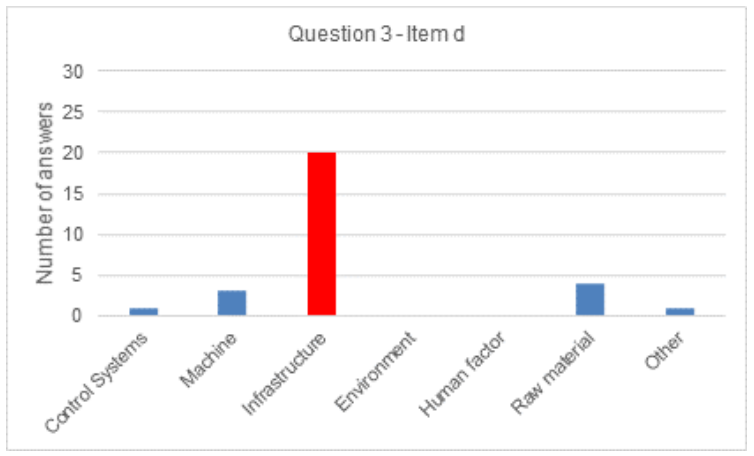

Figure B4 - Answers of all respondents to Item "d" on Question 3. 


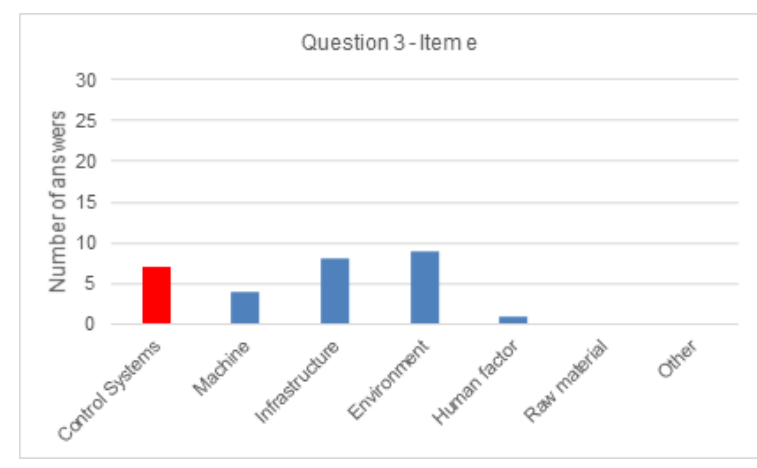

Figure B5 - Answers of all respondents to Item "e" on Question 3.

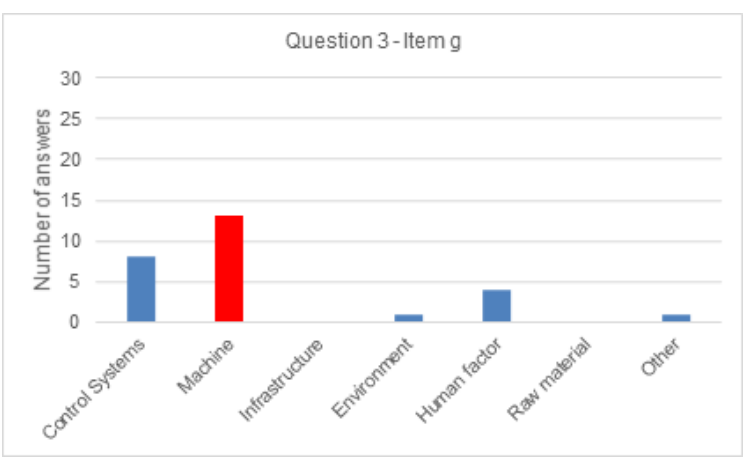

Figure B7 - Answers of all respondents to Item "g" on Question 3.

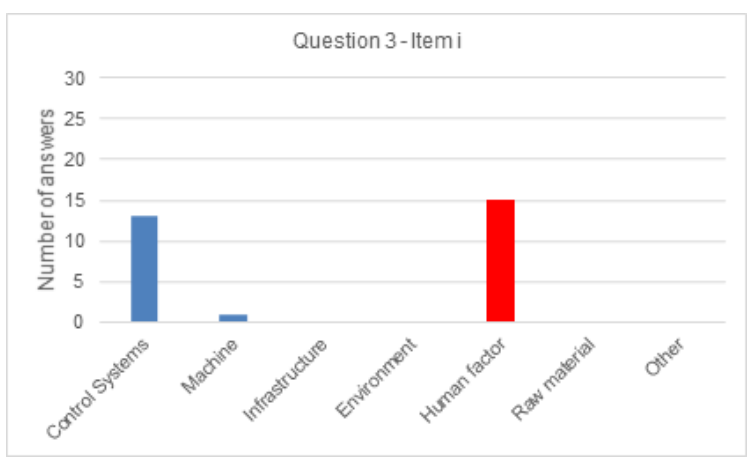

Figure B9 - Answers of all respondents to Item "i" on Question 3.

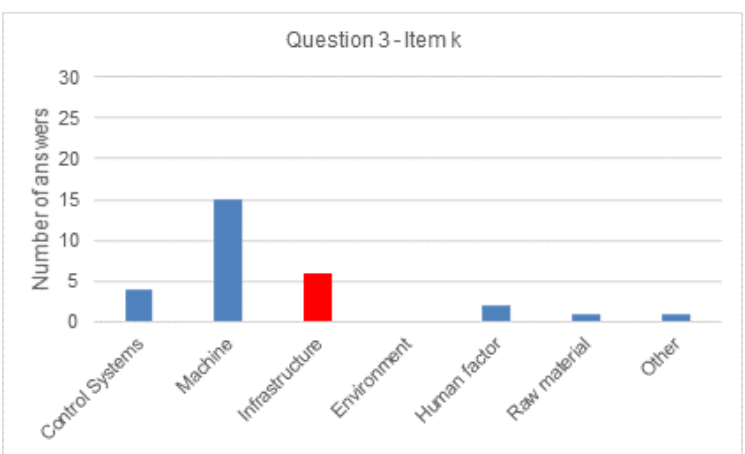

Figure B11 - Answers of all respondents to Item "k" on Question 3.

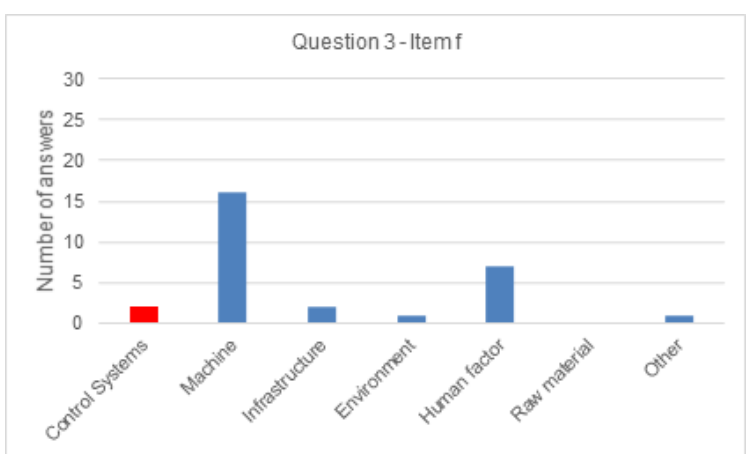

Figure B6 - Answers of all respondents to Item "f" on Question 3.

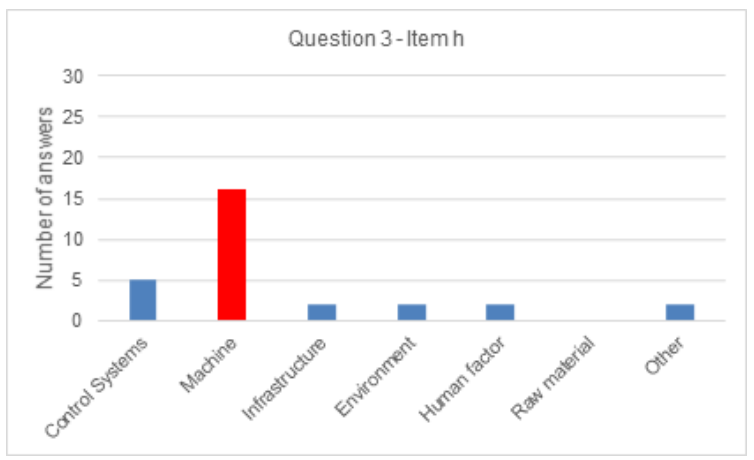

Figure B8 - Answers of all respondents to Item "h" on Question 3.

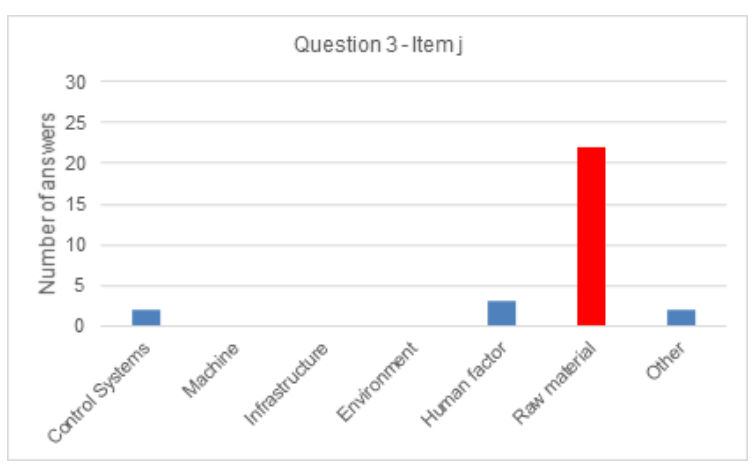

Figure B10 - Answers of all respondents to Item "j" on Question 3.

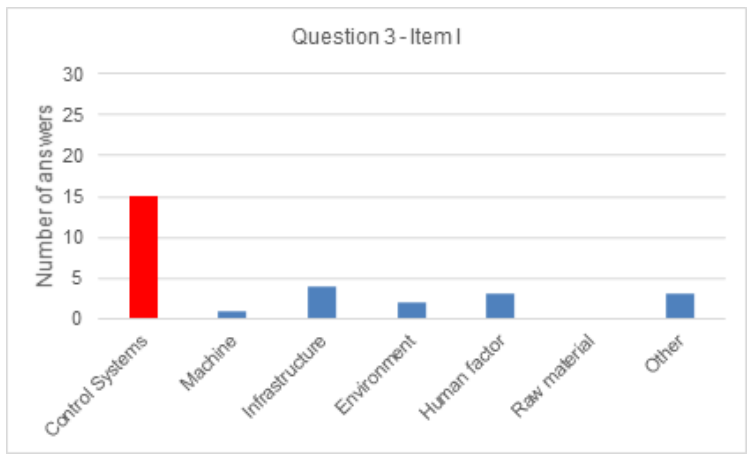

Figure B12 - Answers of all respondents to Item "l" on Question 3. 


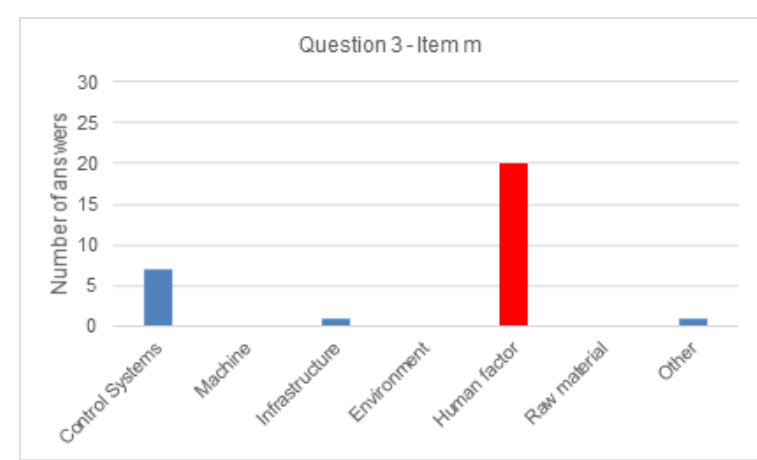

Figure B13 - Answers of all respondents to Item "m" on Question 3.

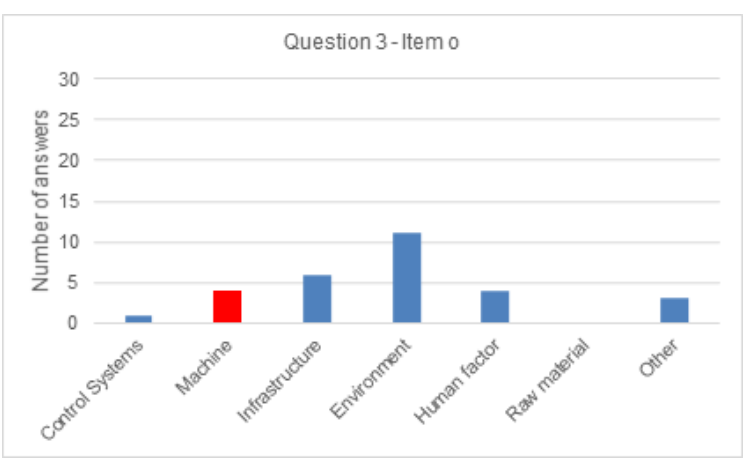

Figure B15 - Answers of all respondents to Item "o" on Question 3.

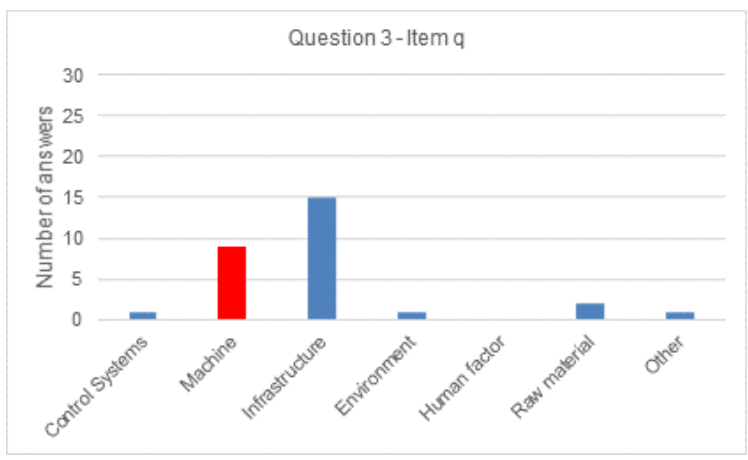

Figure B17 - Answers of all respondents to Item "q" on Question 3.

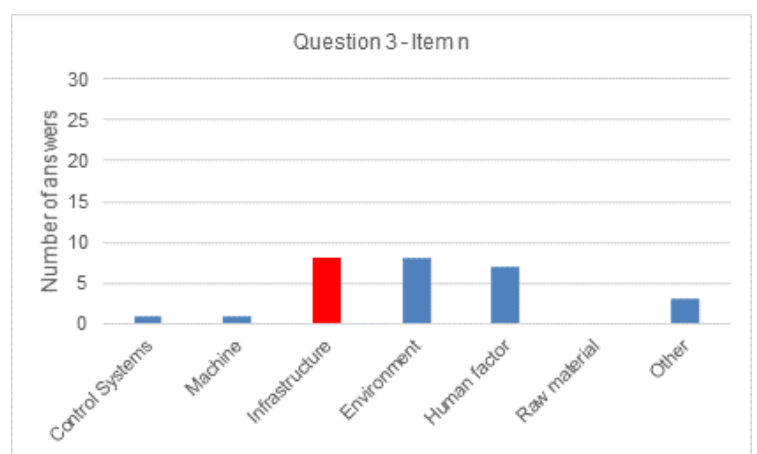

Figure B14 - Answers of all respondents to Item "n" on Question 3.

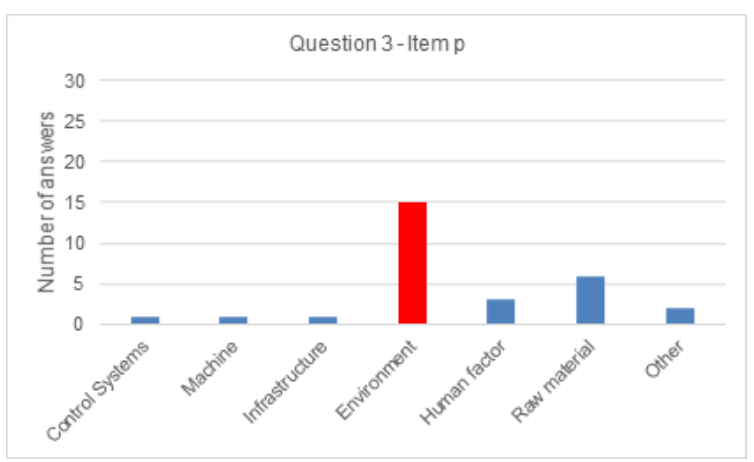

Figure B16 - Answers of all respondents to Item "p" on Question 3.

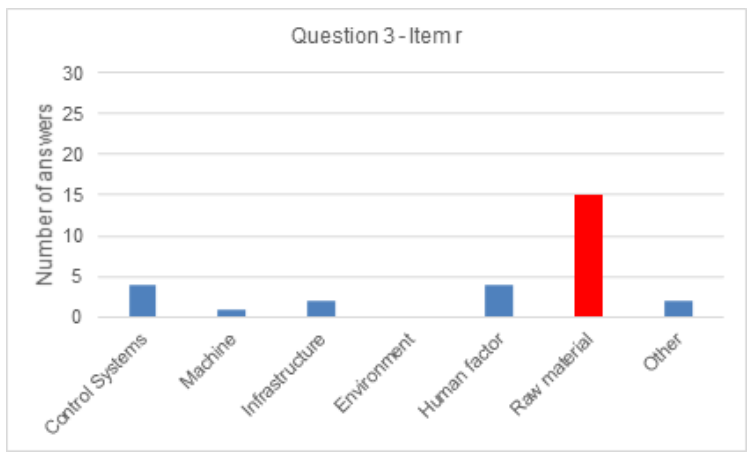

Figure B18 - Answers of all respondents to Item "r" on Question 3. 